\title{
Migraciones en Centroamérica: en la médula de un cambio estructural
}

\section{Ernest Cañada*}

Recibido: octubre de 2011 / Aceptado: noviembre de 2011

Durante las últimas tres décadas Centroamérica ha sufrido una importante transformación en su estructura económica y en su forma de inserción en el mercado internacional. De la agroexportación tradicional se ha pasado a un modelo más diversificado y complejo, en el que adquieren un especial protagonismo la emigración y las remesas como principal fuente de entrada de divisas. Tomando en cuenta esta centralidad, a continuación se analizan los territorios de destino de la migración dentro de la propia Centroamérica, con especial atención a Guanacaste y la Zona Norte de Costa Rica, que han atraído mano de obra nicaragüense asociada a la construcción y el turismo en el primer caso, y a la cosecha de nuevos cultivos para la exportación, como la piña, en el segundo. La precariedad e informalidad que caracteriza el trabajo en estos destinos da pie a la acentuación de la vulnerabilidad de los trabajadores ante sus empleadores. Seguidamente se examinan los impactos provocados en los territorios de origen de la migración, poniendo el acento en cuestiones como la desagregación familiar y comunitaria, el papel contradictorio de las remesas, los procesos de diferenciación social o la afectación sobre los recursos naturales.

Palabras clave: Centroamérica / migración / dinámicas territoriales / trabajo precario / remesas

Sinceramente aqui no se viene a hacer absolutamente nada, nada; más bien a quitarse la vida. Es cierto que tal vez uno gana 50.000 pesos en una semana, que allá tiene que trabajar un mes para sacar esa plata. ¿Pero qué remediamos? Ganar esa plata y venirla a gastar siempre en la comida. A como tal vez le puede servir a uno venir solo, y ni así, porque

* Coordinador de la ONG catalana ALBA SUD - Investigación y comunicación para el Desarrollo (www. albasud.org). Correo electrónico: ernest@albasud.org. 
somos muchos que tal vez nos vamos de parranda, o qué sé yo, y no sirve de todas maneras, pero para mí sinceramente que no. Viene a regalar uno su trabajo, para que otro ahí crezca. Yo dijera que el que la pasa un poquito allá, así con la agricultura, que tenga donde sembrar... es mejor vivir allá.

Carlos Rubén Martínez, trabajador nicaragüense de la construcción en Guanacaste, Costa Rica, agosto de 2010.

\section{Introducción ${ }^{1}$}

Durante las últimas tres décadas en Centroamérica son miles los trabajadores y trabajadoras que cada año tienen que emigrar, tanto a los Estados Unidos como a otros países de la región, para poder sobrevivir y encontrar los recursos necesarios para garantizar el bienestar de sus familias. Se estima que más de dos millones de salvadoreños, cerca de un millón de hondureños, millón y medio de guatemaltecos y entorno a trescientos mil nicaragüenses viven en los Estados Unidos. Por otra parte, la población nicaragüense en Costa Rica asciende a unas setecientas mil personas y sobre las cien mil en El Salvador. Los conflictos armados, la pobreza, un modelo de desarrollo excluyente, la falta de empleo y oportunidades han expulsado a una parte muy destacada de la población centroamericana. Muchos emigran indocumentados. No siempre alcanzan su objetivo y sufren lesiones o fallecen en el trayecto, son deportados y enfrentan violaciones a sus derechos más fundamentales. Sin embargo, las causas estructurales que provocan estos movimientos siguen presentes y la migración no cesa a pesar de todas las dificultades que los migrantes encuentran en el camino (Rocha, 2010).

Los que consiguen llegar a su lugar de destino inician entonces el reto de luchar por un futuro mejor para ellos y sus hijos. El envío de remesas permite que muchas familias centroamericanas mejoren sus condiciones de vida, aunque los costes e impactos de todo tipo que comporta este modelo de desarrollo no son menores. Este creciente peso de las remesas en la economía de Centroamérica pone al descubierto el papel de la región como proveedora de mano de obra barata en el mercado internacional. Esto afecta tanto a los patrones de movilidad de la población centroamericana como a las dinámicas territoriales. La migración se revela, de este modo, como un fenómeno global y complejo que está reconfigurando de forma radical la región.

\section{Las migraciones en el centro de un cambio estructural}

Una de las aristas que mejor reflejan el alcance actual de las migraciones es el enorme peso que adquieren las remesas en las dinámicas económicas de Centroamérica. De hecho, éstas se encuentran en el centro de un cambio estructural en el modelo de inserción de la región en la economía internacional, tal como se desprende del análisis del siguiente cuadro sobre los perfiles de generación de divisas por países y sectores de actividad entre 1978 y 2006 :

1 Este artículo y los distintos testimonios que en él aparecen proceden del trabajo de investigación y producción de recursos comunicativos solicitados por Fundación PRISMA de El Salvador a ALBA SUD. 


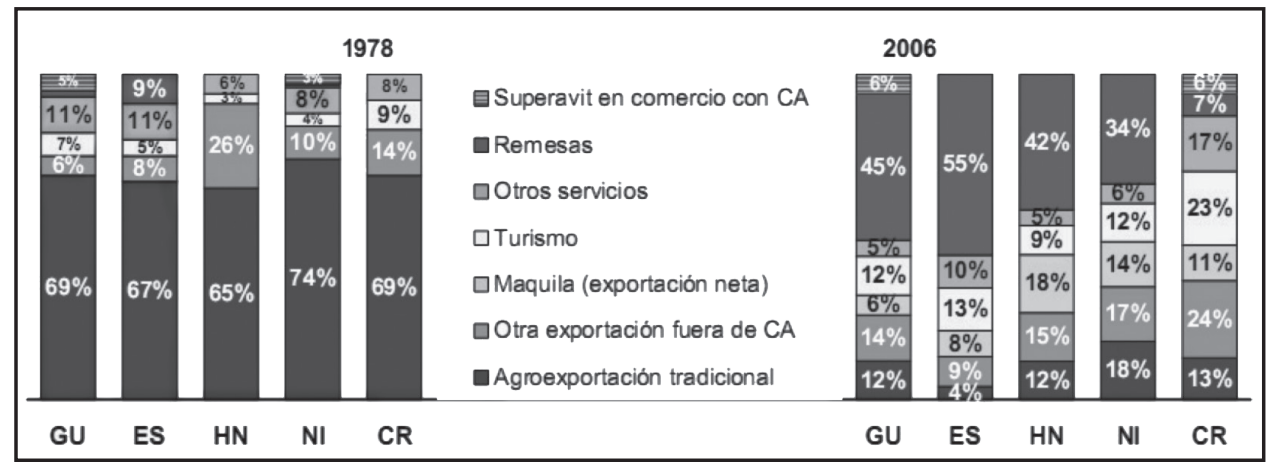

Ilustración 1. Centroamérica: perfiles de generación de divisas, 1978 y 2006 Fuente: Rosa (2008)

De la agroexportación tradicional de hace tres décadas, basada en el algodón, el banano, el azúcar, el café y la carne, principalmente, se ha pasado a una adquisición de divisas a partir de una estructura más compleja y diversificada, con predominio de las remesas, la exportación de productos agrícolas tradicionales y no tradicionales, la maquila y el turismo, principalmente. A excepción de Costa Rica, para el resto de países de la región las remesas eran, justo antes de la crisis económica internacional que inició en el año 2007, su principal fuente de entrada de divisas: en El Salvador: 55\%; en Guatemala: 45\%; en Honduras: 42\%; en Nicaragua: 34\%. Estos datos nos sitúan ante una realidad evidente: Centroamérica se ha integrado a la economía global mediante la exportación de mano de obra barata, o la explotación en el propio territorio del recurso fuerza de trabajo con bajos salarios, destinada a generar productos y servicios orientados al mercado internacional, como la maquila textil o los nuevos cultivos de exportación -palma africana, melón, piña o cítricos- y el turismo. La gran dependencia con respecto al mercado internacional que por diversas vías ha establecido la sociedad centroamericana, supone una fuente creciente de vulnerabilidad que puede expresarse con mayor intensidad en períodos de crisis global.

Este cambio de modelo no puede explicarse únicamente por las dinámicas internas de la región, con la crisis, por ejemplo, de algunos productos de agroexportación tradicional como el algodón -que decayó totalmente en los años ochenta, pasando de las 417.200 hectáreas cultivadas en 1979 a tan sólo 1.600 en el año 2003 en el conjunto de Centroamérica-, sino que hay razones globales que están en el origen de esta transformación (Rosa, 2008, pp. 30-33). De hecho, a excepción del caso ya mencionado del algodón, la superficie y el volumen de exportación de productos tradicionales como el café, el azúcar, el banano o la carne no varió significativamente durante ese período; en cambio, lo que sí se produjo fue una drástica caída del valor real de esas exportaciones. Según el estudio de Herman Rosa citado el valor de la tonelada métrica exportada cayó en el café (65\%), el azúcar (47\%) y la carne (22\%), y solo aumentó ligeramente en el caso del banano (8\%). De este modo, el valor de las exportaciones agropecuarias disminuyó fuertemente en todos los países de la región: 73\% en El Salvador, 58\% en Nicaragua, 29\% en Guatemala, 16\% en Costa Rica y 10\% en Honduras (Rosa, 2008, p. 105). Una 
explicación de las causas de este proceso la encontramos en la caída de los precios internacionales del petróleo en los años ochenta, que abrieron la etapa de "los veinte años de petróleo barato" y que arrastró al resto de materias primas a la baja a causa del incremento del petróleo disponible a nivel mundial y la erosión en la capacidad de control de la Organización de Países Exportadores de Petróleo (OPEP) sobre el mercado del crudo durante esos años (Fernández Durán, 2008, pp. 25-32). Esto supuso un golpe mortal para las economías exportadoras de materias primas y productos agrícolas, que se vieron sometidas a la puesta en marcha de los paquetes de ajuste estructural inspirados en el Consenso de Washington, para poder hacer frente a una deuda creciente.

La caída de la rentabilidad de la agroexportación tradicional provocó que esos capitales transitaran hacia otro tipo de actividades en la búsqueda de mayores garantías para su reproducción ampliada. De este modo empezaron a tomar mayor protagonismo otros sectores, como los cultivos de exportación no tradicionales (frutas como la piña, el melón o los cítricos, o agrocombustibles como la palma africana), el turismo, la maquila, la minería, y otras industrias extractivas, que ocuparon territorios que hasta el momento se habían dedicado a otras actividades, con predominio de los monocultivos, o habían jugado un papel marginal en la economía centroamericana.

La consolidación de este proceso de cambio ha dado lugar a profundas transformaciones en las áreas rurales. Los patrones de ocupación del territorio han variado, y de un esquema más o menos similar basado en la agroexportación tradicional, se ha pasado a la consolidación de múltiples dinámicas territoriales condicionadas por la presencia predominante en una determinada área de alguno de los nuevos ejes de acumulación que dinamizan la economía de la región (Cuéllar et al., 2011, pp. 21-24). Uno de los factores clave de estas nuevas dinámicas territoriales lo constituye la movilidad poblacional que, igualmente, se ha vuelto mucho más compleja. En algunos casos, parte de las poblaciones que ocupaban previamente esas zonas han experimentado presiones de diverso tipo para que las abandonaran, y por otro lado se ha producido un incremento en la demanda de mano de obra permanente o temporal que ha habido que movilizar y desplazar desde otros territorios de la región, pues no siempre estaba disponible en las condiciones requeridas en esos lugares.

En realidad en el viejo modelo agroexportador también se producían fuertes movimientos de población. Periódicamente se necesitaban trabajadores para la recolección del café, la caña de azúcar, el banano o el algodón que, como advierte Nelson Cuéllar, investigador de la Fundación PRISMA, "eran proporcionados desde los sectores de agricultura de subsistencia”, y al acabar el trabajo para el que habían sido requeridos, regresaban a ellos, lo que confería una cierta estabilidad a este sistema. La diferencia es que en la actualidad la agricultura familiar de subsistencia, afectada por la crisis del viejo modelo agroexportador y las migraciones campo-ciudad que acompañaron los grandes procesos de urbanización en Centroamérica desde los años sesenta, no puede satisfacer en su totalidad las necesidades de trabajo que precisan estas nuevas actividades líder de la economía globalizada de la región. Esto ha supuesto que la provisión de mano de obra esté vinculada también a la población urbana empobrecida. Pobreza y vulnerabilidad social se convierten entonces 
en condición necesaria para garantizar los flujos de trabajadores y trabajadoras migrantes. De este modo se configuran nuevos patrones de movilidad mucho más complejos que en el pasado.

\section{Una mirada hacia los lugares de destino dentro de Centroamérica}

La Zona Norte de Costa Rica constituye un ejemplo paradigmático de estos territorios que se han reconfigurado como enclaves orientados a la producción de bienes y servicios para un mercado globalizado y que atraen mano de obra migrante para hacer frente a necesidades que no puede abastecer la propia área. En esta zona existen dos grandes polos de actividad: por un lado, el desarrollo turístico y residencial, que se concentra en las costas de la provincia de Guanacaste, y por otro los cultivos de exportación (piña, melón, cítricos, caña de azúcar, arroz) que se dan en algunas zonas de Guanacaste y de la provincia de Alajuela. Tanto una como otra actividad solicitan grandes cantidades de trabajadores de forma temporal (en el turismo, sobretodo en el proceso de construcción, y en la maquila agrícola en los momentos de cosecha). La existencia de fuertes desigualdades de renta entre Costa Rica y Nicaragua facilita un flujo regular de esta población migrante.

\subsection{Turismo residencial en las costas de Guanacaste}

Antes de que Guanacaste se convirtiera en un destino privilegiado para el turismo, y posteriormente se expandiera la actividad inmobiliaria vinculada al turismo residencial, la provincia se había dedicado principalmente a la ganadería y algunos cultivos tradicionales de agroexportación (Edelman, 1998; Vargas Araya, 2008). Según la economista Marcela Román, entre los años 2003 y 2007 Costa Rica vivió un fuerte crecimiento de la actividad constructiva, hasta que la crisis económica internacional, que empieza a manifestarse en toda su magnitud en el año 2008, hizo decaer la actividad. Durante ese período, las provincias del Pacífico, Guanacaste y Puntarenas, y específicamente los cantones del litoral orientados hacia las actividades turísticas, protagonizaron este fuerte crecimiento de la construcción hasta el punto de concentrar más del $50 \%$ de los nuevos metros cuadrados edificados en Costa Rica. En el caso de Guanacaste, si en el año 2003 el número de nuevos metros cuadrados edificados fue de 208.998, en 2007 ascendió a los 678.926 (Román, 2009, pp. 14-16).

El desarrollo de este nuevo modelo, dirigido a atraer inversiones y turistasresidentes en el mercado internacional, y entre sectores de ingresos altos de la misma Costa Rica, hizo que la provincia se viera afectada por múltiples movimientos de población. Por una parte, en un proceso que ha tendido a ser minimizado e invisibilizado, las poblaciones costeras, especialmente comunidades pesqueras, empezaron a ser acosadas para que se desplazaran de la primera línea de mar, objeto de deseo de la inversión turística y residencial, en el marco de los procesos de regulación promovidos en base a la Ley de Zona Marítimo Terrestre de 1977 (Cañada, 2011a). Por otra parte, grandes contingentes de trabajadores nicaragüenses se desplazaron para la 
construcción de los complejos turísticos, desarrollos inmobiliarios e infraestructuras diversas. Muchos llegaron indocumentados, otros respondían al llamado de las autoridades públicas de Costa Rica. Así, por ejemplo, en el año 2007, en respuesta a las demandas de la Cámara Costarricense de la Construcción (CCC), el Ministerio de Trabajo y Seguridad Social de aquel país recomendó la autorización de la entrada de 10.000 trabajadores extranjeros en las siguientes ocupaciones: maestro de obras, carpintero, albañil, fontanero, soldador, hojalatero, pintor, operador de mármol y granito, y peones (Organización Internacional para las Migraciones [OIM], 2009, pp. 36-37). En su mayoría, estos trabajadores tendieron a ubicarse en algunos barrios periféricos de la ciudad de Liberia, como Martina Augusta -donde más del 80\% de la población es de origen nicaragüense- o bien en campamentos provisionales de las mismas obras en construcción. Y finalmente, la llegada también de nuevos residentes, mayoritariamente norteamericanos y costarricenses de altos ingresos, que fijaron en las costas de Guanacaste su segunda residencia.

El avance de este modelo de desarrollo en Guanacaste, a pesar de su desaceleración a consecuencia de la crisis económica internacional, ha provocado numerosos conflictos con las comunidades rurales que se han visto afectadas por la disputa con los grandes inversionistas de recursos como la tierra y el agua. Organizaciones como la Pastoral Social, FEDEAGUA o la Confraternidad Guanacasteca han jugado un papel muy activo -a pesar de sus diferencias- para acompañar o ponerse al frente de las demandas de numerosas comunidades de la provincia (Cañada, 2011b).

\subsection{La Zona Norte de Costa Rica: la maquila agrícola}

Por su parte, los municipios del interior de la zona Norte de Costa Rica mantuvieron su orientación agrícola previa, pero en este nuevo ciclo de acumulación amplios territorios fueron destinados de forma intensiva a cultivos no tradicionales de exportación como la piña, el melón y los cítricos, que fueron ganando protagonismo frente a los tradicionales. De alguna manera, esta área ilustra el cambio profundo que se produce en la agricultura costarricense en las últimas tres décadas: mientras los cultivos tradicionales reducen mayoritariamente su superficie cultivada (por ejemplo, la extensión de maíz en el conjunto del país pasa de 43.800 a 6.300 hectáreas cultivadas entre 1978 y 2006, y la superficie de frijol se reduce de 27.600 a 14.000 hectáreas), los cultivos no tradicionales aumentan su presencia (como es el caso de la piña, que de sólo 500 hectáreas cultivadas en 1978 aumenta hasta las 38.500 en 2006, o el melón, que de ser prácticamente desconocido, en 2006 se extiende hasta las 11.200 hectáreas). Pero además ganan terreno en relación al valor de su exportación. Los casos del café y la piña ponen claramente en evidencia esta tendencia contradictoria. Mientras la superficie cultivada de café pasó de las 81.000 hectáreas a las 99.000 entre 1978 y 2006, el valor de su exportación disminuyó de los 314 millones de dólares a los 227. Por su parte, la piña, con una superficie cultivada mucho menor, ascendió el valor de su exportación a los 430 millones de dólares en 2006, superando así al café (Rosa, 2008, pp. 18-20).

La concentración en el territorio de este tipo de nuevos cultivos, además de generar una fuerte demanda de mano de obra concentrada en los momentos 
de cosecha y que se desplaza por las plantaciones a lo largo del calendario agrícola, ha significado el progresivo desplazamiento de la pequeña producción familiar campesina por grandes empresas, en su mayoría de capital extranjero, en especial en sectores como la piña (Acuña, 2005).

Asimismo, esta situación ha comportado un uso intensivo de agroquímicos. Según datos del World Resources Institute, con sede en Washington, Costa Rica se habría convertido en el mayor consumidor de plaguicidas del mundo, con 51,2 kg. por hectárea, seguido a mucha distancia en América Latina por Colombia (16,7 Kg.) y Ecuador (6 kg.) (Andreu, 2011). Estos datos concuerdan con los del Instituto Regional de Estudios en Sustancias Tóxicas (IRET) de la Universidad Nacional de Costa Rica que revela que el país aumentó en un 340\% la cantidad de plaguicidas importados entre 1977 y 2006. El uso de estos agrotóxicos se concentra principalmente en el melón, el tomate, la papa, la piña y la caña de azúcar (Andreu, 2011). Este tipo de productos provoca graves impactos ambientales: contaminación del agua, erosión del suelo, pérdida de fertilidad, etc. En este sentido, el Informe del Estado de la Nación publicado en el año 2009, reconocía que desde el año "2001 han venido ocurriendo incidentes de contaminación química, dados por el uso excesivo de plaguicidas en actividades agrícolas tipo monocultivo, como es el caso de la piña", como consecuencia de la "expansión agrícola y urbana, que no ha considerado, ni respetado, las márgenes de protección de las fuentes de captación de agua para consumo humano" (Programa Estado de la Nación, 2009, p. 40). De este modo, la concentración en el territorio de este nuevo modelo de cultivo intensivo para la exportación, se revela como una amenaza para los ecosistemas de la zona (Cuéllar, 2011, pp. 18-20).

\subsection{Precariedad y trabajo informal: vulneración de derechos}

Tanto en el caso de la construcción como en el de los jornaleros agrícolas, la forma como se insertan estos trabajadores en los mercados de trabajo se caracteriza por la precariedad y la informalidad. Según Joan Benach y Carles Muntaner, miembros del Grupo de Investigación en Desigualdades en Salud de la Universidad Pompeu Fabra, en Barcelona, el empleo precario tiene que ver con la temporalidad, la ausencia de poder por parte del trabajador, la exclusión del acceso a prestaciones sociales y los bajos salarios. Por su parte, la informalidad hace referencia a situaciones no reguladas en el mercado de trabajo y que derivan de un acuerdo "informal" entre el empleado y el empresario. Esto implica que los trabajadores informales se ven excluidos de todo tipo de beneficios sociales (como jubilación pagada o bajas por enfermedad y maternidad), garantías laborales (limitaciones en el número de horas trabajadas o indemnizaciones por despido), reciben salarios más bajos o sufren mayor rotación en el empleo (Benach \& Muntaner, 2010, p. 12).

De este modo, los trabajadores migrantes nicaragüenses en la zona Norte de Costa Rica se han insertado en los nuevos mercados de trabajo a medio camino entre la precariedad y la informalidad, según las particularidades de cada sector y empresa en concreto. En el caso de los obreros de la construcción, por ejemplo, un estudio realizado entre empresas de la construcción de Costa Rica durante el año 2008, en el marco de un proyecto de cooperación de la Agencia Española de Cooperación 
Internacional para el Desarrollo (AECID), puso en evidencia que estos obreros "trabajan hasta 12 horas diarias y generalmente no se les reconocen las horas extras (...), trabajan los días feriados”, y que en algunas empresas se pide como requisito "que tengan herramientas" (OIM, 2009, p. 32). Por otra parte, una auditoría interna de la Caja Costarricense de Seguro Social (CCSS) determinó que entre los años 2005 y 2007 el 73\% de los trabajadores de la construcción en Guanacaste carecían de seguro social con el que afrontar "los riesgos de enfermedad, maternidad, invalidez, vejez y muerte", según informó el periódico La Nación (04/07/2007). Esto resulta especialmente grave por cuanto la construcción es una actividad que se lleva a cabo con escasas medidas de seguridad en condiciones de alto riesgo, con lo cual los accidentes y lesiones son frecuentes.

En el caso de los jornaleros agrícolas, sus condiciones laborales son también extremadamente penosas. Según Guillermo Acuña, investigador de la Asociación de Servicios de Promoción Laboral (ASEPROLA), los trabajadores del sector de la piña en Costa Rica tienen que realizar largas jornadas por encima de lo que permite la ley y sus garantías sociales muchas veces no son reconocidas. Además la figura de los contratistas agrava la situación de los trabajadores (Acuña, 2005). A esto hay que añadir el hecho de que con mucha frecuencia se ven expuestos al uso intensivo de agroquímicos, algunos de los cuales revisten una especial toxicidad e incluso están ya prohibidos en Estados Unidos, Canadá o Europa, como denunció el pasado 30 de agosto de 2011 el diputado del Frente Amplio en la Asamblea Legislativa de Costa Rica, José María Villalta, ante los ministerios de Trabajo, Salud, Agricultura y Ambiente, según reporta El País de Costa Rica (30/08/2011). Este es el caso del Carbofurán, distribuido comercialmente bajo la marca Furadán, un insecticida usado ampliamente en las plantaciones de piña para combatir la presencia de gusanos y otras plagas (chinches, cochinillas, taladradores y barrenadores). Este tipo de productos ha generado graves daños en la salud de los trabajadores, que frecuentemente presentan afectaciones en la piel o cuadros clínicos de intoxicación, tal como cuenta el Dr. Alexander Moraga del Centro de Salud de Los Chiles: "usan las bombas para estar regando el veneno en las plantaciones y esto les produce, a nivel de vías respiratorias, malestar, como dolor de cabeza, cefaleas, náuseas, vómitos, mareos, e incluso malestar general, dolores en el cuerpo, en las articulaciones y visión borrosa”. Además la exposición a los rayos directos del sol durante muchas horas ocasiona insolaciones o problemas en la piel.

A estas condiciones laborales se suman otras dinámicas sociales fuera del lugar de trabajo derivadas de la forma en que se producen las migraciones, que agravan las condiciones de vida de estos trabajadores, como son las situaciones de indocumentación, la escasa protección social, los hábitats insalubres o los efectos del desarraigo.

El estado de indocumentación de muchos migrantes dificulta su acceso a determinados servicios e incrementa la vulnerabilidad ante el contratador. Para muchos de ellos los costes para adquirir la documentación requerida son demasiado elevados y prefieren asumir el riesgo y trasladarse de ese modo. Por otra parte, este tipo de situaciones actúa como un mecanismo disciplinar para la fuerza de trabajo, que se integra en los nuevos territorios con escasa capacidad para defender sus derechos. 
A esto hay que añadir la escasa capacidad de vigilancia y control de las autoridades públicas en la región ante la vulneración de derechos o abusos que sufren los trabajadores migrantes. Tampoco los sindicatos han podido desarrollar estrategias y estructuras capaces de integrar y organizar a estos nuevos colectivos laborales, ni en la construcción ni en el sector hotelero, donde por poner un ejemplo, un informe de Enildo Iglesias del 2008 para la Rel-UITA identificaba que ni en un solo hotel gestionado por cadenas de origen español en Costa Rica tenía constituido un sindicato (Iglesias, 2008). En el caso de la construcción, los mecanismos de subcontratación empresarial han dificultado aún más la acción colectiva en defensa de los derechos de los trabajadores. El mismo estudio citado elaborado por la Caja Costarricense de Seguro Social detalla que en 12 proyectos evaluados "se encontraron 349 subcontratos para obras como instalaciones electromecánicas, cielos, pisos y detalles de edificaciones", a lo que los auditores añadían que, "por lo general, los subcontratistas no suscriben planillas para el aseguramiento de sus trabajadores" (OIM, 2009, p. 30).

La crisis económica internacional, iniciada desde finales de 2007 y principios de 2008, provocó una caída radical de la construcción en Guanacaste y en el conjunto de Costa Rica. Según datos proporcionados por la Cámara de la Construcción Costarricense, durante el 2009 el sector decreció un 40\% comparándolo con el año anterior en el conjunto del país, y un 77\% en Guanacaste, tomando como indicador los metros cuadrados en permisos de construcción. A su vez, esto causó la pérdida de más de 24.00 empleos directos (La Nación, 13/12/2009). Fue en esos momentos que la desprotección social en la que vive este colectivo se puso en evidencia en toda su magnitud. Ante la falta de empleo, muchos trabajadores migrantes tuvieron que recurrir a múltiples ocupaciones informales para sobrevivir, como acudir al basurero de Liberia para conseguir comida, tal como relata Langying Hernández, psicóloga de la Pastoral Social de Guanacaste: "al menos un miembro o dos miembros de cada familia han ido una o dos veces al botadero cuando están sin empleo”. De este modo, en muchos territorios, determinadas instituciones eclesiales se han convertido en el principal mecanismo de protección y amparo de los trabajadores migrantes.

Cabe destacar también cómo en la mayoría de los casos ni el sector privado ni las autoridades públicas de los territorios que reciben a los trabajadores migrantes han preparado estructuras de alojamiento para ellos, de tal modo que predomina la provisionalidad de sus viviendas, la autoconstrucción, el hacinamiento y la insalubridad ambiental. En noviembre de 2008, la muerte de un trabajador nicaragüense, Rafael Antonio Pérez, intoxicado en el campamento donde vivía con otros mil quinientos obreros que trabajaban en la construcción del Hotel Riu en Playa Matapalo, Guanacaste, puso al descubierto ante la opinión pública las condiciones insalubres del hábitat de esos trabajadores. Junto a él otros trescientos trabajadores se intoxicaron y padecieron "vómitos, diarreas y males respiratorios", según informó el diario La Nación (16/11/2008).

A todo este tipo de condiciones de trabajo y de vida, hay que sumar los efectos del desarraigo y de la separación familiar, dando como resultado un claro cuadro de estrés psico-social. La búsqueda de salidas en el alcohol u otras formas de evasión contribuye a la degradación de parte de este colectivo, que en la migración 
ha encontrado una vía para conseguir algunos recursos, pero que al mismo tiempo enfrenta un día a día extremadamente penoso.

Tomando en cuenta los distintos impactos que ha provocado en Guanacaste este modelo de desarrollo, la Pastoral Social de Liberia movilizó a decenas de personas de todas las parroquias de la provincia y de organizaciones sociales para elaborar un diagnóstico que acabó convirtiéndose en la Carta Pastoral de Monseñor Victorino Girardi Stellin, obispo de la diócesis de Tilarán-Liberia. En esta carta, del 19 de julio de 2009, la Iglesia Católica hacía una lectura muy crítica del crecimiento tan desmesurado del turismo en la provincia, tanto desde la perspectiva de sus pobladores como de los trabajadores migrantes que se desplazaron hacia allá y de la sostenibilidad del mismo territorio. Esto le llevó a hacer la siguiente petición: "nos unimos al grito angustioso de varias organizaciones guanacastecas que piden declarar, por parte de los gobiernos municipales, una moratoria definitiva a la inversión inmobiliaria, análoga a la moratoria en conexión con el agua, negando nuevos permisos de construcción y tomando las demás medidas que sean necesarias, con el propósito de disminuir el riesgo de un eventual colapso, cuyos efectos podrían llegar a repercutir directamente en el ámbito ecológico, social y económico" (Girardi Stellin, 2009).

\section{Los impactos en los territorios de origen de la migración}

Comoen muchas otras regiones expulsoras de población, la migración centroamericana de estas últimas décadas ha tenido múltiples efectos interrelacionados, derivados de la salida de una parte de su población en determinados territorios y la posterior llegada de remesas, así como la aparición de nuevos migrantes de otros países de la región que ocupan en parte el vacío dejado por los primeros. Los resultados después de diez, quince o veinte años de haberse iniciado estos procesos son sociedades mucho más complejas, diferenciadas y contradictorias que afrontan desafíos enormes de diversa índole con muchas más dificultades.

\subsection{Desagregación familiar y comunitaria}

Una de las primeras y más sentidas consecuencias de la migración en Centroamérica ha sido la separación y la división de las familias a causa de la marcha de los padres y/o las madres y el cuidado de sus hijos e hijas a cargo de otros adultos. Esto ha provocado situaciones dramáticas para muchas familias y ha afectado de diferentes formas el desarrollo personal de los niños, niñas y jóvenes. Con mayor o menor intensidad, este fenómeno ha contribuido a la desarticulación familiar de muchos hogares. La separación afecta la crianza y educación de los menores, que en muchas familias han crecido sin uno de los progenitores, o los dos. También se ha señalado que su acceso a dinero, a través de las remesas, sin estructuras familiares sólidas, ha contribuido al aumento del consumismo y comportamientos que han debilitado la cohesión social en esas comunidades y barrios. En cierta medida, esta ausencia de adultos clave, provocada por la emigración se reproduce también en otras ocupaciones vinculadas a las nuevas formas de acumulación que se dan en la región. Tal es el caso, por ejemplo, de muchas mujeres empleadas en la maquila textil, que se ven 
obligadas a estar fuera de sus casas durante todo el día. Estas dinámicas familiares en contextos de empobrecimiento y exclusión social, como los que se viven en muchos territorios de Centroamérica, en algunos casos han favorecido o han sido caldo de cultivo para el crecimiento de otras formas de agregación y organización social de los jóvenes a nivel territorial, como las maras, que han acabado por provocar un gravísimo problema de delincuencia y seguridad pública y que en estos momentos condicionan cualquier proceso de desarrollo en la región.

Por otra parte, el protagonismo de estos procesos migratorios ha recaído en la gente joven en edad productiva que en muchos casos era la más activa, lo que también ha tenido efectos sobre el tejido social y comunitario. Según Pedro Torres, investigador de la Red de Desarrollo Sostenible - Honduras (RDS-HN), quienes han trabajado ampliamente en el Departamento de Olancho, una zona dedicada tradicionalmente a la ganadería extensiva y con una fuerte emigración hacia el exterior especialmente después del huracán Mitch de 1998, "muchos de estos emigrantes formaban parte de estructuras comunitarias organizadas" y su marcha debilitó el tejido organizativo y las capacidades de desarrollo de las comunidades. Esto provoca un proceso de "descapitalización social" como el que describe Roberto Lemus, vinculado también a RDS-HN: "en zonas de Lempira, principalmente, hay comunidades fantasmas: los jóvenes se han ido y las familias están compuestas por niños, mujeres y ancianos. Esto provoca descapitalización social; es decir, las poblaciones no se pueden organizar, no se pueden cohesionar, debido a que las personas que las integran, que mueven las economías, y que se involucran en el desarrollo han tenido que partir" (Lemus, 2008, pp. 46-47).

\subsection{El papel contradictorio de las remesas}

Uno de los grandes debates que ha acaparado una amplia atención ha sido el impacto de las remesas en las posibilidades de desarrollo de los territorios de origen de los migrantes. En el caso centroamericano ya se ha señalado su importancia como fuente de divisas para países como El Salvador, Honduras, Guatemala y Nicaragua. De hecho, las remesas han sustituido las vías tradicionales de exportación y venta de bienes y servicios como vía principal para la obtención de divisas. Pero más allá de su impacto macroeconómico, la llegada de las remesas tiene importantes y diversos efectos a escala local. Para Abelardo Morales, de FLACSO Costa Rica, las remesas actúan como un sistema de ajuste ante los desequilibrios provocados por el modelo de desarrollo dominante, facilitando de este modo cierta estabilidad social en la medida que "compensan una serie de desigualdades, o al menos crean la ficción de que están resolviendo la pobreza. Y se constituyen en un equilibrador político en la medida que los desajustes sociales, las brechas sociales y las posibles explosiones sociales que estas fracturas puedan tener en los sistemas políticos, se ven reducidas y se convierten en una válvula de escape."

En Centroamérica estas remesas que envían los migrantes desde Estados Unidos oscilan sobre los doscientos y los doscientos cincuenta dólares mensuales (Lemus, 2008, p. 45). Excepcionalmente pueden llegar hasta los cuatrocientos o un poco más, y las que mandan los nicaragüenses desde Costa Rica son significativamente menores. En torno a ellas se desarrollan todo tipo de actividades 
de comercio y servicios vinculadas a su intermediación y al intento de captura de esas rentas. De hecho, el sector bancario se ha convertido en uno de los principales beneficiarios de este flujo de recursos hacia las economías centroamericanas. En el caso de Nicaragua, por ejemplo, el Banco de la Producción (BANPRO) recibe y canaliza un promedio de 10 millones de dólares mensuales en remesas (Mora, 2009, p. 16). Lorenzo Cruz, sacerdote de la parroquia de Santa Rosa de Lima en el Departamento de La Unión, El Salvador, donde según datos del PNUD el 46\% de los hogares reciben remesas, advierte también sobre este crecimiento del sector bancario en torno a las remesas, cuando dice: "Es exagerado cómo están los bancos acaparando todo este tipo de actividad económica." Brian Bil Lunas, director de una agencia bancaria en la misma localidad, explica con evidente satisfacción el esfuerzo de la banca para hacerse con el control completo de las remesas familiares: "Tratamos de que se hagan clientes nuestros y ofrecerles, más que todo, cultura del ahorro. Que ellos tengan cuenta, no importa la cantidad que manejen en su cuenta, lo bueno es ahorrar. Y eso es lo que tratamos como banco, (...) hacerlos clientes y que se culturicen en el ahorro." Y en torno a esos ahorros se desarrollan diversos productos y servicios bancarios.

Las remesas facilitan un incremento del consumo familiar en distintos tipos de productos y servicios, dinamizando fuertemente el comercio y la economía local, incluyendo algunas actividades ilícitas, como el coyotage. En primera instancia, permiten a muchas familias salir de las deudas que habían contraído y que, en algunos casos, estuvieron en el origen de la migración, y hacer frente a sus necesidades más básicas (alimentación, vestido, educación, salud). Es conocido que, en la medida que pueden hacerlo, las familias de los migrantes invierten también en la mejora de sus casas o en la construcción de nuevas viviendas.

\subsection{Diferenciación social}

Es precisamente en torno a las mejoras de las viviendas que se han visualizado con mayor claridad los procesos de diferenciación social que acaba generando la migración y las remesas en el ámbito local. En los municipios rurales son claramente reconocibles las casas de las familias que cuentan con remesas y las que no. Según Xenia Ortiz, investigadora de Fundación PRISMA, el caso de Santa Rosa de Lima resulta ilustrativo: "los que reciben remesas como ya empiezan a comprar viviendas en la zona, hay una proliferación también de lotificaciones, y empieza a subir el coste de la vivienda, el coste de los terrenos, y es algo que la gente que reside aquí no va a poderlo pagar, no lo puede pagar de hecho. En ese sentido es que la migración y la entrada de remesas también está acentuando la exclusión ya existente.”

De este modo, las familias que reciben remesas poco a poco van desarrollando pautas de consumo particulares, hasta el punto de ser identificados como otro grupo social -sentencia Ortiz- que goza de mayores oportunidades para su desarrollo. Pueden optar, por ejemplo, a una mejor atención en salud, ya que tienen capacidad económica para pagar las medicinas recetadas, o acceder si es necesario a un servicio médico privado; tienen también la posibilidad de mejorar su dieta alimentaria, con la incorporación de productos que antes les resultaban prohibitivos; o pueden ampliar sus opciones educativas, especialmente en el bachillerato o en estudios 
técnicos, que habitualmente se encuentran más dispersos geográficamente, y por tanto generan mayores gastos en transporte, o sencillamente porque disponen de más tiempo para estudiar sin necesidad de incorporarse a tiempo completo en el mercado laboral. En consecuencia, no sólo se produce una diferenciación social entre los que disponen de remesas y los que no, sino que como producto de la entrada de remesas en la economía local, el acceso a servicios y determinados bienes se vuelve más complicado para unos que para otros porque aumenta el coste de la vida y todo se vuelve más caro, y esto hace que "los salvadoreños que están fuera de los circuitos migratorios sean el núcleo duro de la pobreza en las áreas rurales”, según explica Susan Kandel, investigadora de Fundación PRISMA. Este grupo de los más pobres es el que depende en mayor medida de la agricultura de subsistencia, aunque sean los que menos pueden acceder a ella y los que tienen menos posibilidades de diversificar sus fuentes de vida, ocuparse en empleos no agropecuarios o emigrar (Kandel \& Cuéllar, 2011).

De hecho, este proceso de diferenciación e incremento de la complejidad de los territorios que originalmente expulsaron población hacia la migración, se agudiza aún más con la llegada de nuevos migrantes procedentes de zonas más empobrecidas que vienen a ocupar el déficit de mano de obra dejado en esas poblaciones, especialmente en actividades generadoras de escasas rentas, como la agricultura, por ejemplo. Este tipo de movimientos de población, conocido como "migraciones de relevo", es el que se da en algunos lugares de El Salvador con la llegada de trabajadores hondureños y, sobre todo, nicaragüenses. Las condiciones de empleo de estos trabajadores, que acostumbran a viajar con visado pero sin permiso de trabajo, son especialmente duras. Este tipo de migración tiene una elevada temporalidad y año con año se van estableciendo redes de contactos para cubrir las necesidades de mano de obra en determinados momentos.

Por otra parte, y con un impacto a menor escala aún, otros movimientos de población de nuevo tipo, vinculados a la migración originaria de trabajadores y trabajadoras centroamericanos hacia los Estados Unidos, son los desplazamientos periódicos hacia sus lugares de origen que realizan los migrantes que han logrado alcanzar un estatus legal en ese país y una cierta comodidad económica. En muchas ocasiones regresan acompañados de sus familias y con hijos nacidos ya en los Estados Unidos. Dado el volumen de migrantes centroamericanos en los Estados Unidos, este segmento particular de migrantes reconvertidos puntualmente en turistas se ha convertido en una oportunidad para el desarrollo de actividades de comercio y ocio vinculadas a la recreación de la cultura local, la memoria histórica, la gastronomía, etc. En el caso de El Salvador, por ejemplo, la Fundación PRISMA ha reiterado en diversas publicaciones el potencial de este sector para el fortalecimiento del turismo rural comunitario, en la medida que su oferta conecta claramente con los intereses de ese colectivo (PRISMA, 2009a; PRISMA, 2009b; Gómez \& Ortiz, 2011).

\subsection{Impactos en los recursos naturales}

La llegada de remesas en algunos territorios ha tenido también efectos sobre los recursos naturales. Las investigaciones desarrolladas por la Red de Desarrollo Sostenible de Honduras (RDS-HN) en el departamento de Olancho han dado cuenta 
de un proceso muchas veces oculto en el que la llegada de remesas ha aumentado las amenazas sobre unos frágiles ecosistemas.

En este caso, a medida que las familias que recibían remesas fueron resolviendo los problemas de deudas, atención a necesidades básicas y mejora de sus viviendas, empezaron también a hacer algunas inversiones productivas. El Departamento tradicionalmente se ha dedicado a la ganadería extensiva y a algunos cultivos de exportación como el café, por lo que las inversiones que han priorizado los migrantes y sus familias se concentraron también en la ganadería y cultivos orientados hacia la exportación. De este modo priorizaron aquellas actividades que más ingresos en metálico podían proporcionarles en detrimento de producciones orientadas a garantizar la alimentación familiar o para el mercado local. El problema que se encontraron, tal como explica Pedro Torres, es que "en la parte baja, o en los valles, era muy difícil encontrar terrenos, y si encuentras los precios son exageradamente elevados. Lógicamente la parte donde ellos pueden tener acceso a terrenos es donde hay bosque". El resultado fue un incremento de la deforestación y la conversión de esas parcelas de montaña en potreros donde sembrar pastos para alimentar al ganado.

Por otra parte, las familias que recibían remesas tienden a desarrollar prácticas productivas menos amigables con el medio ambiente. En términos generales, las familias que no reciben remesas tienen parcelas de menor extensión que constituyen su principal medio de vida, por lo que como esa "es la única fuente de ingresos que tienen, por lo tanto tratan de conservarla, aplicando técnicas que contribuyen a mejorar la fertilidad del suelo y lógicamente a tener mayor rendimiento en el proceso de producción”, explica Pedro Torres. Por el contrario, para las familias que disponen de ese otro tipo de ingresos, "la actividad agrícola como tal y la actividad ganadera, (...) es una estrategia para generar o acumularse un poco de riqueza, pero no es una estrategia fundamental de vida de la familia”, apunta Wilmer Reyes, profesor de la Universidad Nacional de Agricultura (UNA) en Olancho, por lo que no tienen la necesidad de hacer el esfuerzo que implica ese tipo de prácticas. El resultado es que el incremento de recursos en manos de familias que en su momento tuvieron que emigrar por falta de oportunidades, acaba reforzando un modelo productivo que presiona los recursos naturales y amenaza su sostenibilidad.

Por otra parte, las investigaciones realizadas por la Fundación PRISMA en El Salvador ahondan en el análisis de las relaciones entre migraciones, remesas y recursos naturales. Entre sus conclusiones destaca que si bien la migración y la recepción de remesas entre familias de determinadas zonas rurales está provocando una mayor desvinculación de la tierra debido a que las familias dependen menos de la agricultura para garantizar su seguridad alimentaria y aumentan las actividades noagrícolas -comercio y servicios, particularmente-, en una lógica de desarrollo mucho más urbana, esto ha provocado cambios en las pautas de consumo que suponen una nueva fuente de impacto sobre los recursos naturales. El incremento en la generación de basura y una mayor demanda de agua se convierten en factores de presión sobre unos ecosistemas ya frágiles (Rosa, Kandel \& Cuéllar, 2006, p. 30). 


\section{Conclusiones}

El balance final en torno al papel protagonista de las migraciones y las remesas en el nuevo modelo de acumulación que se inició en Centroamérica entre finales de los años setenta y principios de los años ochenta no resulta muy positivo, especialmente desde la perspectiva de los grupos más desfavorecidos. La población centroamericana ha pagado un coste muy alto por unos modelos de acumulación que, lejos de promover un desarrollo endógeno y con mayores niveles de equidad, han tratado de insertarse en la economía global en base a la sobreexplotación de la fuerza de trabajo y los recursos naturales. Por otra parte, la región se ve afectada por nuevas presiones y dinámicas territoriales que generan una mayor diversificación y complejidad, lo que dificulta cada vez más el desarrollo de políticas públicas más integradoras, socialmente justas y sostenibles.

\section{Referencias bibliográficas}

Acuña, G. (2005). La actividad piñera en Costa Rica. Impactos, consecuencias y desafíos. Servicio de Información Regional de la Rel-UITA. Recuperado el 5 de agosto de 2011 de www.rel-uita.org.

Andreu, T. (2011, 5 de septiembre). Costa Rica: Número uno del mundo en uso de agroquímicos. El País Costa Rica.

Benach, J. \& Muntaner, C. (2010). Empleo, trabajo y desigualdades en salud: una visión global. Barcelona: Icaria Editorial.

Cañada, E. (2011a). Costa Rica: comunidades costeras en lucha. Entrevista: Wilmar Matarrita. Colección Opiniones en Desarrollo - Programa Turismo Responsable, (12). Barcelona: Alba Sud.

Cañada, E. (2011b). Conflictividad turística en Centroamérica. En M. Blàzquez \& E. Cañada (eds.). Turismo placebo: Nueva colonización turística: del Mediterráneo a Mesoamérica y El Caribe. Lógicas espaciales del capital turístico. (pp. 163-208). Managua: Editorial Enlace.

Cuéllar, N., Kandel, S., Davis, A., Díaz, O., Luna, F. \& Ortiz, X. (2011). Dinámicas territoriales en Centroamérica: Contexto y desafíos para comunidades rurales. San Salvador: Fundación PRISMA.

Edelman, M. (1998). La lógica del latifundio. San José: CIHAC.

Fernández Durán, R. (2008). El crepúsculo de la era trágica del petróleo. Pico del oro negro y colapso financiero (y ecológico) mundial. Bilbao: Virus Editorial \& Ecologistas en Acción.

Girardi Stellin, V., Monseñor. (2009). Carta Pastoral. Discípulos, tras las huellas de Cristo, promoviendo la vida en él, al Norte de Costa Rica. Liberia: Diócesis de Tilarán-Liberia.

Gómez, I. \& Ortiz, X. (2011). La apuesta por un turismo sostenible en El Salvador: Propuestas para un cambio de políticas. En M. Blàzquez \& E. Cañada (eds.). Turismo placebo: Nueva colonización turística: del Mediterráneo a Mesoamérica y El Caribe. Lógicas espaciales del capital turistico. (pp. 209-248). Managua: Enlace Editorial. 
Iglesias, E. (2008). Las cadenas hoteleras españolas en América Latina y las libertades sindicales. Montevideo: Rel-UITA.

Kandel, S. \& Cuéllar, N. (2011). Migración, medios de vida rurales y manejo de recursos naturales: Lecciones de El Salvador. San Salvador: Fundación PRISMA.

Lemus, R. (2008). El fenómeno migratorio en las familias minifundistas y sin tierra del Occidente de Honduras. En AAVV. Memoria. El fenómeno migratorio. Oportunidades y desafíos en la región del Occidente de Honduras. Tegucigalpa: Editorial Guaymuras.

Mora, A. (2009). Remesas, envíos de esperanza. El Observador Económico. (203), septiembre.

Organización Internacional para las Migraciones [OIM]. (2009). Demanda laboral del sector construcción en Costa Rica y su componente migratorio. San José: Infoterra Editores.

PRISMA. (2009a): Turismo y desarrollo sostenible: Avanzar en la descentralización, inclusión y participación local. Aportes para Políticas, (2). San Salvador: Fundación PRISMA.

PRISMA. (2009b). Un viraje necesario en la política turística bajo el nuevo gobierno en El Salvador. Aportes para Políticas, (4). San Salvador: Fundación PRISMA.

Programa Estado de la Nación en Desarrollo Humano Sostenible. (2009). Decimoquinto Informe Estado de la Nación. San José: Programa Estado de la Nación.

Rocha, J. L. (2010). Expulsados de la globalización. Políticas migratorias y deportados centroamericanos. Managua: INHCA-UCA.

Román, M. (2009). Dinámica en el mercado inmobiliario en la Costa Pacífica de Costa Rica. Informe final. San José: Center for Responsible Travel - CREST.

Rosa, H. (2008). Perfiles y trayectorias del cambio económico en Centroamérica: Una mirada desde las fuentes generadoras de divisas. San Salvador: Fundación PRISMA.

Rosa, H., Kandel, S. \& Cuéllar, N. (2006). Dinámica Migratoria, Medios de Vida Rurales y Manejo de Recursos Naturales en El Salvador. San Salvador: Fundación PRISMA.

Vargas Araya, R. (2008). Conflictos en torno a la tenencia de la tierra en Guanacaste (Costa Rica) y posiciones asumidas al respecto por algunos actores políticos y religiosos: un aporte desde la Doctrina Social de la Iglesia. Tesina de Maestría no publicada, Universidad de Salamanca, Salamanca, España. 